Accordingly the resection rate was over $90^{\circ}{ }_{0}$, with $43^{\circ}{ }_{0}$ surviving five or more years.

Despite the age of the patient symptoms and signs should often lead to suspicion of cancer. Endoscopic examination and barium enema should be more frequently used in its detection.

\section{References}

Ahfelı, F. (1880). Archiv für Gynäkologie, 16, 135

Dukes, C. E. (1940). Fournal of Pathology and Bacteriology, 50, 527

Ehrlich, J. C., and Hunter, O. B. (1947). Surgery, Gynecology and Obstetrics with International Abstracts of Surgery, 85, 98.

Goligher, J. C. (1967). In Surgery of the Anus, Rectum and Colon, 2nd edn., p. 555 . London, Baillière, Tindall, and Cassell.
Michener, W. M., Gage, R. P., Sauer, W. G., and Stickler, G. B. (1961). Ner: England fournal of Medicine, 265, 1075.

Millar, D. (1970). Quoted by Pemberton, M. (1970). British fournal of Surgery, 57, 841 .

Naunton Morgan, C. (1971). Fournal of the Royal College of Surgeons of Edinburgh, 16, 71 .

O'Brien, S. E. (1967). Canadian Medical Association fournal, 96, 1217.

Recio, P., and Bussey, H. J. R. (1965). Proceedings of the Royal Socicty of Medicine, 58, 789.

Rosato, F. E., Frazier, T. G., Copeland, E. M., and Miller, I. D. (1969). Surgery, Gynecology and Obstetrics with International Abstracts of Surgery, 129, 29.

Rosi, P. A. (1969). In Diseases of the Colon and Anorectum, ed. R. Turell, 2nd edn., p. 478. Philadelphia, Saunders.

Sessions, R. T., and Riddel, D. J. (1961). American fournal of Surgery, 102, 66.

Sessions, R. T., Riddel, D. J., Kaplan, H. J., and Foster, J. H. (1965) Annals of Surgery, 162, 279.

Whiteside, J. A. (1971). American fournal of Proctology, 22, 367

\title{
Resistance of Haemophilus influenzae to Trimethoprim
}

\author{
J. ROBERT MAY, JUDITH DAVIES
}

British Medical fournal, 1972, 3, 376-377

\section{Summary}

Out of 210 isolates of Haemophilus influenzae obtained from the sputum of 63 patients with chronic respiratory infections $109\left(52^{\prime}\right)$ were resistant to trimethoprimsulphamethoxazole by the disc test. The minimal inhibitory concentrations of trimethoprim for 17 out of 18 strains recorded as resistant were $10 \mathrm{~kg} / \mathrm{ml}$ or higher. Resistant strains were isolated from time to time from 32 $\left(82^{\prime \prime}{ }^{\prime \prime)}\right.$ out of 39 patients known to have been treated with trimethoprim-sulphamethoxazole, compared with only $1\left(12 \cdot 5^{\circ}\right)$ out of 8 patients known not to have been treated with this drug combination. Resistant strains were isolated most frequently from patients who had received long-term treatment. Since sulphamethoxazole penetrates from the blood into the bronchial secretions less readily than does trimethoprim it seems likely that the ratio of the two drugs in the bronchial tree is far from ideal. This may be an important factor in the use of these drugs for chest infections.

\section{Introduction}

The minimal inhibitory concentration (M.I.C.) of trimethoprim for Haemophilus influenzae is usually about $0 \cdot 1-1 \mu \mathrm{g} / \mathrm{ml}$ (Bushby, 1969), but Waterworth (1969) reported the isolation in our laboratory of two strains for which the M.I.C.s were 32 and $16 \mathrm{~kg} / \mathrm{ml}$ respectively. Commenting on this observation, Garrod and O'Grady (1971) remarked: "Such emergence of resistance so relatively early in the drug's therapeutic history must again be taken as a warning that it should not be used for infections which are almost certainly not of bacterial origin, for trivial infections which do not require antibacterial therapy, or for infections which can equally successfully and conveniently be treated with something else." Our experience of the occurrence of trimethoprim-resistant $H$. influenzae during the past four years strongly reinforces the need for this warning. We report here the details of this experience.

\footnotetext{
Department of Bacteriology, Institute of Diseases of the Chest, Brompton Hospital, London S.W.3

. ROBERT MAY, M.D., F.R.C.PATH., Professor

JUDITH DAVIES, B.SC., Research Assistant
}

\section{Material and Methods}

The survey is based on the findings of routine sensitivity tests of 210 isolates of $H$. influenzae cultured from the sputum of 63 patients investigated between June 1968 and February 1972. Forty-five patients were suffering from cystic fibrosis and 18 had other chronic respiratory disorders-namely, chronic bronchitis, asthma, bronchiectasis, or bronchial carcinoma.

Sensitivity Tests. - It is well known that tests of sensitivity of micro-organisms to trimethoprim and sulphonamides can give erroneous results if the medium used for the tests contains large amounts of the end-products of folate metabolism (Bushby, 1969). These "inhibitors" enable the organism to escape the blockade of folate synthesis and thus to grow in the presence of the drugs. In consequence, organisms may appear to be drugresistant when they are, in fact, sensitive. When confronted with an unexpectedly high rate of resistance to these drugs, therefore, it is necessary to scrutinize the possibility of experimental error of this origin. Accordingly we describe below, firstly, our routine test procedure and, secondly, tests carried out to confirm or refute the findings.

Routine Sensitivity Test Procedure.-Routine sensitivity determinations were carried out by the filter-paper disc method, using standard discs (Oxoid) containing $25 \mathrm{~kg}$ of a mixture of trimethoprim (1 part) and sulphamethoxazole (19 parts). Nutrient agar plates (see below) were flooded with six-hour broth cultures of the test strains diluted $1 / 100$. The excess was pipetted off and the plates were dried at $37^{\circ} \mathrm{C}$, the discs applied, and the plates incubated at $37^{\circ} \mathrm{C}$ overnight. Three types of result were observed: (1) complete inhibition of growth around the disc; (2) an "inhibition zone," but containing minute colonies throughout; and (3) normal growth around the disc. A strain was recorded as being drug-resistant if the zone of complete inhibition extended for less than $2 \mathrm{~mm}$ from the edge of the disc. The culture medium used for these tests was based on the meat-digest broth devised by Breach and his colleagues at Westminster Hospital (Baker and Breach, 1967). To this were added $\mathrm{X}$ factor (haemin, B.D.H.) and $\mathrm{V}$ factor (nicotinamide adenine dinucleotide, B.D.H.) to a final concentration of 3 and $0.3 \mathrm{mg} / 100 \mathrm{ml} \mathrm{w} / \mathrm{v}$ respectively. Lysed horse blood, at a final concentration of $0.5^{\circ} \%$, was also added in order to clear the medium of inhibitors of trimethoprim and sulphonamides (Bushby; 1969; Waterworth, 1969).

Confirmatory Tests.-Twenty-four strains were available for repeat tests. These took the form of estimations of the M.I.C.s of trimethoprim on media known to be free from inhibitorsnamely, Diagnostic Sensitivity Test Agar (D.S.T.A., Oxoid) 
and Wellcome Nutrient Agar-to each of which 5" "lysed horse blood was added together with $\mathrm{X}$ and $\mathrm{V}$ growth factors. Plates were poured of these media containing serial dilutions of trimethoprim ranging from $20 \mu \mathrm{g}$ to $0.6 \mu \mathrm{g} / \mathrm{ml}$, and three-hour broth cultures of the organisms were streaked on each. After overnight incubation at $37 \mathrm{C}$ the M.I.C. for each organism was noted as the lowest concentration of trimethoprim in the presence of which no growth could be seen.

\section{Results}

Routine Tests.-Of the $210 \mathrm{H}$. influenzae isolates tested 109 $\left(52^{\prime \prime}{ }_{0}\right)$ were found to be resistant to the trimethoprim-sulphamethoxazole disc. Most of the 63 patients from whom the isolates were obtained had undergone repeat examinations over many months. Resistant strains were isolated at one time or another from 40 patients $\left(63^{\circ}{ }_{0}\right)$. In many instances sensitive strains were also found from time to time, suggesting that the patients were often infected with more than one strain of $H$. influenzae. It should be noted that many of the strains recorded as resistant showed, at first glance, inhibition zones around the disc, but closer inspection revealed minute colonies growing throughout the zone. This phenomenon is discussed further below.

M.I.C.s.-M.I.C.s of trimethoprim were determined for 24 strains on D.S.T.A. $+5^{\circ}$, lysed blood. In the routine test 18 of these had been recorded as "resistant," and their M.I.C.s were: 14 strains $>20 \mu \mathrm{g} / \mathrm{ml}, 3$ strains $10 \mu \mathrm{g} / \mathrm{ml}$, and 1 strain $1.2 \mu \mathrm{g} / \mathrm{ml}$. Of six strains recorded as "sensitive" the M.I.C.s for five were $0.6-2.5 \mathrm{\mu g} / \mathrm{ml}$, while that for the remaining one was $>20 \mu \mathrm{g} / \mathrm{ml}$. The latter was the only strain showing a gross discrepancy between the two types of test. M.I.C.s for four strains were determined on Wellcome Nutrient Agar $+5^{\circ}$ lysed blood and compared with those on D.S.T.A. In each instance the M.I.C. on both media was $>20 \mu \mathrm{g} / \mathrm{ml}$. As with the disc tests the growth of resistant strains in the presence of the higher concentrations of trimethoprim usually consisted of minute colonies, and the end-points of titrations were seldom clear-cut. This appearance was also noted by Miss Pamela Waterworth, to whom the strains were sent for independent examination.

Occurrence of Resistant Strains in Relation to Treatment.Thirty-nine patients were known to have been treated with trimethoprim-sulphamethoxazole. Resistant $H$. influenzae was isolated from time to time from $32\left(82^{\circ}{ }_{i .}\right)$ of them. In contrast

Occurrence of Trimethoprim-resistant $\mathrm{H}$. influenzae in the Sputum of Patients with Chronic Respiratory Infections and its Relation to Treatment with Trimethoprim-sulphamethoxazole $(T-S)$

\begin{tabular}{|c|c|c|c|c|}
\hline \multirow[t]{2}{*}{ Clinical category } & \multirow[t]{2}{*}{ Treatment with $\mathrm{T}-\mathrm{S}$} & \multirow[t]{2}{*}{ No. } & \multicolumn{2}{|c|}{$\begin{array}{c}\text { Patients from Whom } \\
\text { Resistant } \\
\text { H. influenzae } \\
\text { was Isolated }\end{array}$} \\
\hline & & & No. & "。 \\
\hline $\begin{array}{l}\text { All patients .. } \\
\text { Patients with cystic fibrosis } \\
\text { Patients with other disorders }\end{array}$ & 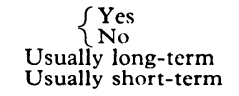 & $\begin{array}{r}39 \\
8 \\
32 \\
7\end{array}$ & $\begin{array}{r}32 \\
1 \\
28 \\
4\end{array}$ & $\begin{array}{l}82 \\
12 \cdot 5 \\
87 \cdot 5 \\
57\end{array}$ \\
\hline
\end{tabular}

only $1\left(12.5^{\prime} \%\right)$ resistant strain was found among the strains isolated from each of 8 patients who, so far as was known, had not taken trimethoprim-sulphamethoxazole. It was not possible to analyse precisely the occurrence of resistant strains in relation to duration of treatment, since regimens varied enormously. In general, however, it seems justified to distinguish between the patients with cystic fibrosis, who were often given long courses of treatment, and those with other diseases, whose treatment was usually shorter. Thus $H$. influenzae was isolated on various occasions from 32 patients with cystic fibrosis known to have been treated with trimethoprim-sulphamethoxazole, $28\left(87 \cdot 5^{\circ},\right)$ yielding resistant strains from time to time. In comparison $4\left(57^{\circ}{ }_{10}\right)$ of the strains isolated from each of 7 patients with other disorders treated with trimethoprim-sulphamethoxazole were resistant to the mixture. These findings are summarized in the Table.

\section{Discussion}

The occurrence of small colonies within the inhibition zone in a disc test for sensitivity to trimethoprim is suggestive of inadequate clearance of inhibitors from the medium (Waterworth, 1969), and for this reason we initially doubted the validity of our routine findings. However, observation of the same phenomenon in the M.I.C. estimations, on media which all authorities would accept as being free from inhibitors, seems to eliminate the possibility of this technical error.

We must conclude, therefore, that the risk of emergence of trimethoprim-resistant $H$. influenzae in patients undergoing long-term treatment is very high indeed, and it is pertinent to re-examine certain aspects of the pharmacokinetics of trimethoprim and sulphamethoxazole.

Synergy between the two drugs in vitro is maximal when the ratio of their concentrations is the same as that of the individual M.I.C.s of each drug for the test organism (Bushby, 1969). For most bacterial species this ratio is about 1 part trimethoprim to 20 parts sulphonamide. Commercially available therapeutic preparations (Septrin, Bactrim) contain one part trimethoprim to five parts sulphamethoxazole, which, after differential absorption from the bowel, give a $1: 20$ ratio of concentrations in the blood. Unfortunately, however, sulphamethoxazole penetrates from the blood into bronchial secretions far less readily than does trimethoprim, and the resulting ratio there is of the order of $1: 1$ (Reeves, 1971). As a result not only would the antibacterial activity of the drugs be expected to be suboptimal in respiratory infections but the value of the sulphonamide in reducing the risk of emergence of trimethoprimresistant strains would be largely lost.

It is possible that this defect might be remedied by greatly raising the dose of sulphamethoxazole for the treatment of respiratory infections, although it is probable that considerations of toxicity would preclude an increase sufficient to give a 20 -fold increase in the concentration attainable in bronchial secretions. Even so, there is clearly a case for the use of dose ratios of trimethoprim and sulphonamide more closely related to the needs of the site of the infection being treated; and official recognition of the acceptability of a single mixture, under the name "co-trimoxazole," to be used for infections in any situation, is regrettable.

We wish to thank Miss Pamela Waterworth for her advice and for examining some of our strains, and Mrs. C. R. Laughton for technical help.

\section{References}

Baker, F. J., and Breach, M. R. (1967). Handbook of Bacteriological Technique, 2nd edn., p. 76, London, Butterworths.

Bushby, S. R. M. (1969). Postgraduate Medical fournal, 45, Suppl., p. 10.

Garrod, L. P., and O'Grady, F. W. (1971). Antibiotic and Chemotherapy, 3rd edn., p. 46, London, Livingstone.

Reeves, D. S. (1971). Fournal of Clinical Pathology, 24, 430

Waterworth, P. M. (1969). Postgraduate Medical fournal, 45, Suppl., p. 21. 